\title{
Metabolism of Natural Killer Cells and Other Innate Lymphoid Cells
}

\author{
Jingjing Cong ${ }^{1,2 \star}$ \\ ${ }^{1}$ Hefei National Laboratory for Physical Sciences at Microscale, The CAS Key Laboratory of Innate Immunity and Chronic \\ Disease, Division of Life Sciences and Medicine, School of Basic Medical Sciences, University of Science and Technology of \\ China, Hefei, China, ${ }^{2}$ Institue of Immunology, University of Science and Technology of China, Hefei, China
}

\section{OPEN ACCESS}

Edited by:

Laurent Brossay,

Brown University, United States

Reviewed by:

Zhongjun Dong,

Tsinghua University, China

Zhengfan Jiang,

Peking University, China

Timothy Edward O'Sullivan,

University of California, Los Angeles,

United States

Emilie Narni-Mancinelli,

INSERM U1104 Centre

d'immunologie de Marseille-Luminy

(CIML), France

*Correspondence:

Jingjing Cong

cjji@mail.ustc.edu.cn

Specialty section:

This article was submitted to

NK and Innate Lymphoid Cell Biology,

a section of the journal

Frontiers in Immunology

Received: 24 April 2020

Accepted: 23 July 2020

Published: 28 August 2020

Citation:

Cong J (2020) Metabolism of Natural Killer Cells and Other Innate Lymphoid

Cells. Front. Immunol. 11:1989.

doi: 10.3389/fimmu.2020.01989
Natural killer (NK) cells are the host's first line of defense against tumors and viral infections without prior sensitization. It is increasingly accepted that NK cells belong to the innate lymphoid cell (ILC) family. Other ILCs, comprising ILC1s, ILC2s, ILC3s and lymphoid tissue inducer (LTi) cells, are largely non-cytotoxic, tissue-resident cells, which function to protect local microenvironments against tissue insults and maintain homeostasis. Recently, evidence has accumulated that metabolism supports many aspects of the biology of NK cells and other ILCs, and that metabolic reprogramming regulates their development and function. Here, we outline the current understanding of ILC metabolism, and describe how metabolic processes are affected, and how metabolic defects are coupled to dysfunction of ILCs, in disease settings. Furthermore, we summarize the current and potential directions for immunotherapy involving targeting of ILC metabolism. Finally, we discuss the open questions in the rapidly expanding field of ILC metabolism.

Keywords: natural killer cells, innate lymphoid cells, metabolism, glycolysis, oxidative phosphorylation

\section{INTRODUCTION}

Innate lymphoid cells (ILCs) represent a heterogeneous population of lymphocytes, which do not generate genetically rearranged antigen receptors, but instead express germline-encoded activating, and inhibitory receptors (1-4). Based on their requirements for developmental transcription factors, cell surface marker expression, and patterns of cytokine production, ILCs are classified into group 1 ILCs [including natural killer (NK) cells and ILC1s], group 2 ILCs (ILC2s), and group 3 ILCs [including ILC3s and lymphoid tissue inducer (LTi) cells] (1-5). ILCs regulate a wide variety of immunological processes. Specifically, NK cells are cytotoxic and defend against tumors and viral infections, mainly through production of cytotoxic granules, interferon (IFN)- $\gamma$, and tumor necrosis factor (TNF) (6). ILC1s are generally non-cytotoxic and respond to intracellular pathogens, such as viruses and Toxoplasma gondii, through secretion of IFN- $\gamma$ and TNF (7-9). ILC2s produce the type 2 cytokines interleukin (IL)-4, IL-5, IL-13, and amphiregulin, which function in anti-helminth immunity, allergic inflammation, and tissue repair (10-14). ILC3s react to extracellular bacteria and fungi through the action of IL-17 and IL-22 (15-18), while LTi cells promote the development of secondary lymph nodes in a lymphotoxin-dependent manner (19). Further, recent evidence indicates that ILCs can mediate memory responses; a feature of adaptive lymphocytes (20-24).

Metabolic pathways are regulated by intrinsic and extrinsic signals to fulfill the energy and biosynthetic needs for cell growth, survival, and specialized functions (25). Glycolysis and mitochondrial oxidative phosphorylation (OXPHOS) are primary metabolic pathways for ATP 
generation (26). Glucose fuels both pathways and is first converted to pyruvate via glycolysis, then metabolized to lactate, or transported into the mitochondria for OXPHOS. Glutamine and fatty acids (FAs) can also fuel OXPHOS through glutaminolysis and fatty acid oxidation (FAO), respectively. Glycolysis generates two ATP molecules from one glucose molecule, whereas up to 36 ATP molecules are gained per single molecule of glucose via OXPHOS. Despite its low efficiency, glycolysis can rapidly produce energy and also supplies biosynthetic precursors that facilitate the survival of rapidly proliferating cells $(27,28)$. In the context of immunity, appropriate metabolic alterations are required in immune cells to ensure a productive immune response; for example, production of cytotoxic granules and cytokines by NK cells and non-NK ILCs $(25,29-33)$. In contrast, dysregulation of NK cell metabolism leads to their dysfunction, and is often associated with disease (34-37). In this review, we provide an overview of the current understanding and gaps in knowledge regarding the metabolism of NK cells and other ILCs (Figure 1), and consider novel therapeutic strategies in which ILC metabolism could be targeted.

\section{BASIC NK CELL METABOLISM}

At steady state, murine NK cells display a metabolically quiescent phenotype and preferentially utilize glucose-fueled OXPHOS (38, 39). This inactive but efficient metabolic pattern is sufficient to meet their biosynthetic and energy demands, even in the context of activation by short-term cytokine stimulation or activating receptor ligation (39). Low levels of glycolysis and OXPHOS are also observed in unstimulated human peripheral blood NK cells (40).

In humans, NK cells are generally divided into two subsets, according to expression of CD56: CD56 ${ }^{\mathrm{dim}}$ cells and CD56 ${ }^{\text {bright }}$ cells. The vast majority of NK cells in the peripheral blood are CD56 ${ }^{\text {dim }}$ NK cells, which have a well-differentiated phenotype and potent cytotoxicity, whereas the less mature CD56 ${ }^{\text {bright }} \mathrm{NK}$ cells are predominant in secondary lymphoid tissues and are the main producers of cytokines (41-44). Recent studies have shown that the two subsets are metabolically distinct, which, at least in part, accounts for their different functions. In response to cytokine stimulation, CD56 ${ }^{\text {bright }} \mathrm{NK}$ cells, probably by virtue of higher cytokine receptor expression, show more pronounced metabolic changes and are more sensitive to metabolic inhibition than CD56 ${ }^{\text {dim }}$ NK cells (40). The CD56 ${ }^{\text {bright }}$ NK cells can be further divided into tissue-resident and circulating subsets. Liverand spleen-resident CD56 ${ }^{\text {bright }}$ subsets exhibit lower expression of the glucose transporter GLUT1, but higher expression of the Lamino acid transporter CD98, following IL-12/IL-15 stimulation, relative to CD56 ${ }^{\text {bright }} \mathrm{NK}$ cells from paired peripheral blood (45). These differential expression profiles of nutrient transporters in NK cells from different tissues may relate to the preference of NK cells for specific nutrients in these compartments, which may further influence the circulating and tissue-resident characteristics of NK cells. Identifying the unique metabolic profile of NK cells in diverse tissues will help to solve this issue.
Mouse NK cells mainly originate and develop in the bone marrow, and then migrate to peripheral tissues. They are characterized into four subsets, based on the expression of $\mathrm{CD} 27$ and $\mathrm{CD} 11 \mathrm{~b}$, from immature to mature: $\mathrm{CD}_{27}^{-} \mathrm{CD}^{-} 1 \mathrm{~b}^{-}$,

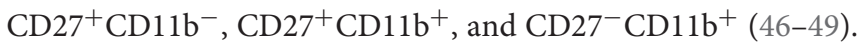
The metabolic activity of NK cells changes dynamically during development (38). Immature NK cells have higher metabolic activity, which is important to support their proliferative expansion. As NK cells mature, pathways related to proliferation are downregulated, and there is a concomitant decrease in the expression of CD98 and the transferrin receptor CD71, as well as glucose uptake, while pathways associated with quiescence are upregulated (38).

Further, during NK cell maturation, they undergo an "education" process, which is generally mediated by inhibitory receptors (KIR in humans and Ly49 in mice), and confers NK cell functional competence, as well as their capacity to distinguish between normal and abnormal cells $(50,51)$. In humans, metabolic reprogramming toward glycolysis and OXPHOS supports the cytotoxic responses of educated NK cells, while uneducated NK cells rely entirely on OXPHOS for this function (52). Thus, activation of glycolysis may be an important mechanism that accounts for the functional difference between educated and uneducated NK cells. In mice, Marcais et al. found that mechanistic target of rapamycin (mTOR) activity is essential for NK cell education, and that the higher mTOR activity in educated NK cells contributes to maintenance of their optimal reactivity and metabolic parameters (53).

Metabolic regulation in NK cells is driven by intricate molecular mechanisms, among which mTOR is the most widely studied. mTOR is a serine threonine kinase and functions as two different complexes, mTORC1 and mTORC2, that differ in their regulation and targets (54). mTORC1 activity is important for the development and functions of NK cells through regulating metabolism; however, little is known about mTORC2 in this regard. In mice, mTOR activity is higher in $\mathrm{CD} 27^{+} \mathrm{CD} 11 \mathrm{~b}^{-}$ $\mathrm{NK}$ cells than $\mathrm{CD}_{2} 7^{+} \mathrm{CD} 11 \mathrm{~b}^{+}$and $\mathrm{CD} 27^{-} \mathrm{CD} 11 \mathrm{~b}^{+}$subsets, suggesting a progressive loss of mTOR activity as NK cells mature (38). Decreased mTOR activity of mature NK cells is associated with their reduced metabolism and proliferative potential (38, 49). Indeed, mTOR-deficient NK cells exhibit a drastic block of differentiation in the bone marrow at the $\mathrm{CD} 27^{+} \mathrm{CD} 11 \mathrm{~b}^{-}$to $\mathrm{CD}_{27}{ }^{+} \mathrm{CD} 11 \mathrm{~b}^{+}$stage, due to compromised proliferation (38).

mTOR activity is required for increased glycolysis and mitochondrial functions during NK cell activation. Pharmacological inhibition of mTOR by rapamycin reduces the upregulation of glycolysis in mouse NK cells stimulated by IL-2/IL-12, and leads to a decrease in mitochondrial mass and membrane potential in human NK cells stimulated by IL-2, resulting in impaired effector functions $(36,55)$. Consistently, CD56 bright $\mathrm{NK}$ cells that exhibit stronger metabolic responses to IL-2 or IL-12/IL-15 stimulation, have higher mTOR activity compared with CD56 ${ }^{\mathrm{dim}}$ NK cells (40); however, excessive activation of mTOR can cause mitochondrial fragmentation, thereby damaging mitochondrial function (37).

mTOR is also involved in metabolic regulation via other molecules, such as sterol regulatory element-binding protein 


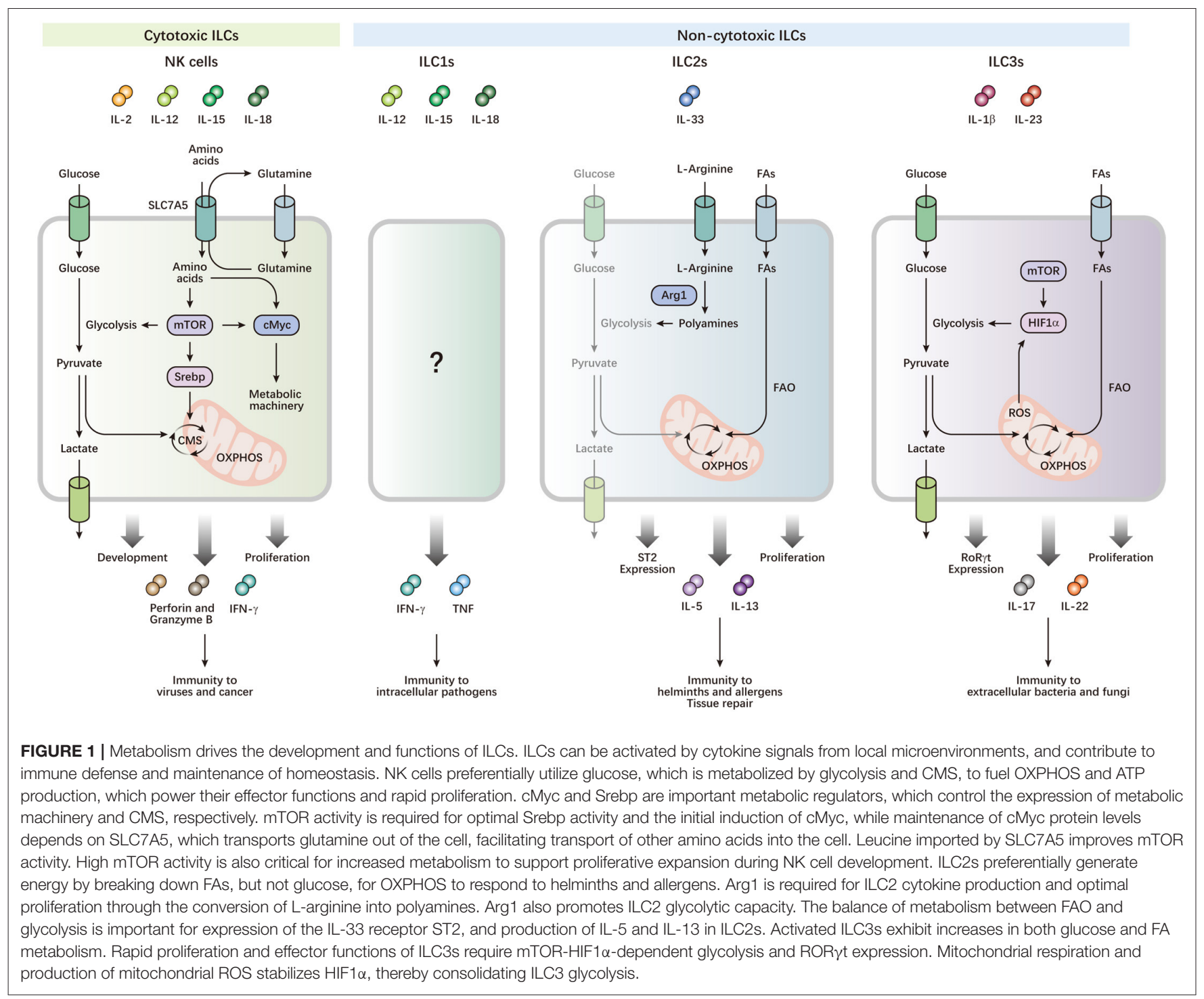

(Srebp) and cMyc. Srebp and cMyc control activation-induced metabolic reprogramming in NK cells, and mTOR is required for optimal Srebp activity and the initial induction of $\mathrm{cMyc}(56,57)$.

\section{METABOLISM AND NK CELL FUNCTION}

It is increasingly accepted that cellular metabolism is indispensable for the activation and specialized functions of immune cells $(58,59)$. For NK cells, metabolic reprogramming is closely involved in multiple immunological processes, where metabolic changes facilitate the generation of energy and biosynthetic precursors to achieve specialized functions.

\section{Effector Function}

NK cells are the first line of defense against infected and transformed cells by production of cytokines and release of cytotoxic granules. NK cell effector functions are controlled by the cytokine milieu, and integration of activating and inhibitory signals on targets $(6,60)$. Acquisition of full effector functions in NK cells requires substantial metabolic reprogramming. Different activation stimuli cause distinct cellular metabolic changes. Generally, NK cell activation by receptor ligation is more metabolically dependent than that in response to cytokine stimulation (39).

In the case of IL-2/IL-12 activation, activated mouse NK cells exhibit increased glycolysis, OXPHOS, glucose uptake, and lipid synthesis $(55,56)$. Glucose is the primary fuel driving enhanced glycolysis and OXPHOS in such activated NK cells. Following cytokine stimulation, glucose is first converted to pyruvate through glycolysis, and then some pyruvate is metabolized to lactate; however, unlike in other lymphocytes, almost no pyruvate is fed into the tricarboxylic acid (TCA) cycle. In NK cells, this pyruvate is metabolized to cytosolic citrate via the citratemalate shuttle (CMS) to fuel OXPHOS and ATP synthesis, a process controlled by Srebp (56). Inhibition of glycolysis or CMS significantly diminishes IFN- $\gamma$ production and Granzyme 
B expression in NK cells $(55,56)$. Although lipid synthesis is essential for the metabolic reprogramming of effector $\mathrm{T}$ cells, inhibition of lipid-synthesis pathways has minimal effects on NK cell effector functions and proliferation (56, 61, 62). Glutamine is another important fuel for metabolically active cells, as glutaminolysis feeds into the TCA cycle, and is not a critical fuel for powering OXPHOS in activated NK cells. Nevertheless, glutamine availability is essential for NK cell metabolism and effector functions as it contributes to sustaining cMyc levels (57). cMyc plays an important role in the metabolic regulation of $\mathrm{NK}$ cells because it controls the expression of metabolic machinery, including glucose transporters and glycolytic enzymes, which are required to support increased metabolism during NK cell activation (57). Glutamine helps the uptake of amino acids essential for high rates of $\mathrm{cMyc}$ protein synthesis through the Ltype amino acid transporter SLC7A5, counteracting continuous cMyc degradation, and thereby maintaining cMyc expression in NK cells. Withdrawal of glutamine or blockade of amino acid transport, leads to cMyc loss and concomitant impaired effector functions (57). As important nutrients, whether FAs can fuel NK cells remains unknown. In fact, FA administration can suppress NK cell effector functions and metabolism (35). Thus, NK cells preferentially utilize glucose, which is metabolized by glycolysis and CMS, to power effector functions. Mechanistically, metabolic activation is essential for NK cells to produce effector protein, including IFN- $\gamma$ and Granzyme $\mathrm{B}$, and to form a correct immunological synapse with target cell (35, 55).

In the case of IL-2 or IL-12/IL-15 activation, CD56 bright $\mathrm{NK}$ cells preferentially upregulate the nutrient receptor CD71 and CD98 in an mTOR-dependent manner, compared with CD56 dim NK cells (40). Further, CD56 $6^{\text {bright }}$ NK cells express higher levels of GLUT1 at baseline, allowing them to rapidly uptake glucose upon activation. Inhibition of glycolysis significantly diminishes IFN- $\gamma$ production by CD56 $6^{\text {bright }} \mathrm{NK}$ cells, while it had minimal effect on degranulation or Granzyme B induction in CD56 ${ }^{\text {bright }}$ or CD56 ${ }^{\text {dim }}$ NK cells (40). Overall, CD56 $6^{\text {bright }}$ NK cells are more metabolically active than their CD56 ${ }^{\mathrm{dim}} \mathrm{NK}$ counterparts, and this assists CD56 ${ }^{\text {bright }} \mathrm{NK}$ cells in their rapid production of large amounts of IFN- $\gamma$ during immune responses.

The effect of IL-15 on NK cell function is dose-dependent; at low concentrations it maintains their survival, while at higher concentrations it promotes activation and proliferation (63-65). Accordingly, a dose-dependent effect of IL-15 on NK cell metabolism is also observed. Recent studies have found that low doses of IL-15 do not induce metabolic changes, while high doses of IL-15 increase glycolysis and OXPHOS in NK cells, with a bias toward glycolysis, possibly because only high doses of IL-15 trigger mTOR signaling $(38,39)$. Interestingly, continuous exposure to low doses of IL-15 exhausts NK cells via repressing their metabolism (66). In terms of in vivo functions, glycolysis is essential for NK cell cytotoxicity and murine cytomegalovirus (MCMV) control, but it does not influence IFN- $\gamma$ production, which suggests that immunometabolism has different effects on NK cell cytotoxicity and cytokine secretion (67). Moreover, IL-15 priming can reduce this glycolytic requirement for NK cell cytotoxicity, highlighting the therapeutic potential of IL-15 in viral infections (67).

\section{Memory Formation}

Immune memory has long been considered a characteristic of the adaptive immune system; however, recent studies have demonstrated that NK cells also generate long-term memory responses against acute viruses, haptens, and cytokine stimulation (20-22). After exposure to stimuli, NK cells undergo expansion and contraction, and eventually form a pool of memory NK cells, with enhanced function, upon encountering the same stimuli. Using a mouse model of MCMV infection, O'Sullivan et al. found that mitochondrial quality in NK cells exhibited dynamic changes from the clonal expansion phase to the memory phase (68). The proliferative burst of NK cells leads to mitochondrial depolarization and accumulation of mitochondrial-associated reactive oxygen species (ROS). During the subsequent contraction-to-memory phase transition, a protective autophagic process, called mitophagy, is induced, which promotes the generation of NK cell memory through removal of dysfunctional mitochondria and ROS (68). Inhibition of mTOR by rapamycin or activation of AMPK by metformin increases autophagic activity, and this further improves the survival of memory NK cells (68). Similarly, metformin also facilitates memory formation in mouse $\mathrm{CD}^{+} \mathrm{T}$ cells (69). There is evidence that mitochondrial FAO is essential for memory $\mathrm{CD}^{+} \mathrm{T}$ cell development, and that metformin stimulates FAO in $\mathrm{CD}^{+} \mathrm{T}$ cells during viral infection $(69,70)$. Furthermore, autophagy deficiency in $\mathrm{CD}^{+} \mathrm{T}$ cells leads to dysregulated mitochondrial FAO (71). Thus, it will be interesting to investigate the relationship between FAO, mitophagy, and NK cell memory.

There have been recent reports that $\mathrm{NKG}_{2} \mathrm{C}^{+} \mathrm{NK}$ cells, which highly co-express CD57, expand and persist in the peripheral blood of humans infected with human cytomegalovirus (HCMV). These cells possess memory-like properties, and are referred to as adaptive NK cells (72-74). Compared with nonadaptive NK cells, adaptive NK cells display a more metabolically active phenotype, mainly manifested as increased glycolysis, mitochondrial respiration and mitochondrial membrane potential, elevated ATP synthesis, and increased glucose uptake (75). Mechanistically, adaptive NK cells upregulate the expression of chromatin-modifying transcriptional regulator AT-rich interaction domain 5B (ARID5B), which enhances mitochondrial metabolism by inducing genes encoding components of the electron transport chain, highlighting a link between epigenetics and metabolism (75).

In other studies, it has been demonstrated that NK cells that recall respiratory influenza virus and skin contact hypersensitive chemical hapten reside in the liver, but not in the infection or sensitization site $(20,76)$. Wang et al. further demonstrated that hapten-specific memory NK cells are generated in the lymph nodes $(23,77)$. These findings raise the question of whether the formation and long-term maintenance of memory NK cells requires a unique nutritional and metabolic environment, which differs among tissues. Furthermore, it remains unclear whether there are variations in the metabolism of memory NK cells induced by different stimuli, such as cytokines and haptens. 


\section{NK CELL METABOLISM IN DISEASE}

NK cell function and metabolism are highly integrated. Dysregulated cellular metabolism of NK cells has been documented in cancer, obesity, and chronic viral infection, and is an important cause of NK cell dysfunction in these diseases.

\section{Obesity}

Obesity is associated with an increased incidence of cancer and infections (78-80), which may, at least in part, be due to NK cell dysfunction, since NK cells in the peripheral blood of obese humans (both adults and children) exhibit reduced cell frequencies, diminished cytotoxicity, and impaired IFN$\gamma$ production $(35,81,82)$. Similarly, downregulated effector molecule expression was observed in spleen NK cells from obese mice fed on high-fat diet (HFD) (35). One recent study illustrated how obesity affects NK cell function by regulating intrinsic cellular metabolism (35). Obesity induces robust activation of peroxisome proliferator-activated receptor (PPAR), which contributes to NK cell uptake of lipids. This lipid accumulation inhibits the mTOR pathway, cMyc expression, and activationinduced metabolic reprogramming, leading to loss of NK cell function (35).

Unlike spleen and peripheral blood, adipose NK cells are overactivated in obese mice fed on HFD. These NK cells expand faster and produce more IFN- $\gamma$ and TNF, which induces the formation of proinflammatory macrophages and further promotes insulin resistance and inflammation $(83,84)$. This seeming paradoxical state may be caused by their unique local microenvironments, as obesity increases the expression of the ligands of NK cell activating receptor NCR1 on adipocytes, thereby stimulating the IFN- $\gamma$ production and local expansion of NK cells (83). Moreover, obesity could drive the secretion of IL15 by adipose tissue macrophages, which has been demonstrated to have a positive effect on NK cell metabolism, proliferation and activation (84). In addition to NK cells, it is recently found that IL-12 activation of ILC1s is also implicated in driving obesity-associated adipose tissue inflammation $(85,86)$. In summary, these studies suggest that obesity leads to the overaction of adipose NK cells, but loss of function of peripheral NK cells, which further contributes to obesity-related pathology and attenuated immunosurveillance, respectively.

\section{Cancer}

NK cells provide potent protection from tumors; however, tumor cells can evade immunosurveillance by inducing NK cell dysfunction through a range of mechanisms. Indeed, NK cells isolated from tumors are decreased in cell number and/or exhibit impaired functions compared with non-tumor NK cells in patients with lung cancer, liver cancer, prostate cancer, pancreatic cancer, and colorectal liver metastasis (37, 87-91). TGF- $\beta$ is a pleiotropic cytokine that is frequently upregulated in tumors, and is believed to have a negative impact on NK cell function. Inhibition of cellular metabolism is an important mechanism responsible for TGF- $\beta$-induced NK cell dysfunction in the tumor microenvironment (Figure 2) (92). Our previous findings showed that the gluconeogenic enzyme fructose-1,6bisphosphatase (FBP1) is induced in NK cells during tumor development in a Kras-driven lung cancer model. Aberrant FBP1 expression, potentially caused by TGF- $\beta$, elicited NK cell dysfunction by suppressing glycolysis and compromising cell viability. Notably, pharmacological inhibition of FBP1 could restore glycolysis, and thus improve NK cell effector functions (34). On the other hand, Slattery et al. found that peripheral blood NK cells from patients with metastatic breast cancer had impaired mTOR activity, profound metabolic defects, and altered mitochondrial morphology. Blocking elevated TGF- $\beta$ ex vivo improved mTOR activity, metabolic parameters, and IFN $-\gamma$ production of NK cells in these patients (36).

Rapid proliferation is a hallmark of cancer. The rapid proliferation of tumor cells leads to a lack of glucose, glutamine, and oxygen, while there is accumulation of plentiful metabolites, such as lactic acid, in the tumor microenvironment (93-97). Recent work from Zheng et al. underlined a detrimental role of hypoxia in NK cell mitochondrial metabolism. They found that tumor NK cells had small, fragmented mitochondria in patients with liver cancer, which was a consequence of hypoxiainduced excessive mitochondrial fission. This mitochondrial fragmentation impaired the cytotoxicity and survival of NK cells, thereby resulting in immune evasion (37).

Glucose consumption by tumor cells weakens $\mathrm{T}$ cell glycolysis and their capacity to produce IFN- $\gamma$ in a mouse sarcoma model (94). Although NK cells generate energy primarily by breaking down glucose to fuel glycolysis and OXPHOS $(39,56)$, it remains unclear how tumor-mediated glucose restriction impacts NK cell metabolism and function. As FBP1 is a critical enzyme for gluconeogenesis, a process that generates glucose, it is reasonable to predict that aberrant FBP1 expression in NK cells may also be a consequence of glucose deprivation. In addition, given the importance of glutamine availability for sustaining cMyc expression (57), tumor-driven glutamine deprivation may dampen NK cell antitumor function by inhibiting metabolism. However, it is necessary to investigate the authentic effects of tumor-imposed metabolic restrictions on NK cells to validate these hypotheses and guide development of effective treatment.

Lactic acid accumulated in the tumor microenvironment is a potent inhibitor of NK cell effector function and viability (90, 98-100). Intracellular acidification and decreased ATP synthesis caused by lactic acid may be related to impaired IFN$\gamma$ production by NK cells (99). A more recent study in patients with colorectal liver metastasis showed that tumor-derived lactic acid led to accumulation of mitochondrial ROS by decreasing intracellular $\mathrm{pH}$, leading to apoptosis of liver-resident NK cells (90). Other metabolites, such as adenosine, prostaglandin $\mathrm{E}_{2}$ $\left(\mathrm{PGE}_{2}\right)$, and kynurenine, which are frequently increased in the tumor microenvironment, also repress NK cell function, and kynurenine has been reported to cause human NK cell apoptosis via ROS (101-105).

\section{Chronic Viral Infection}

In the context of chronic infections, such as with human immunodeficiency virus 1 (HIV-1) and hepatitis B virus (HBV), the immune system fails to clear the virus, leaving NK 


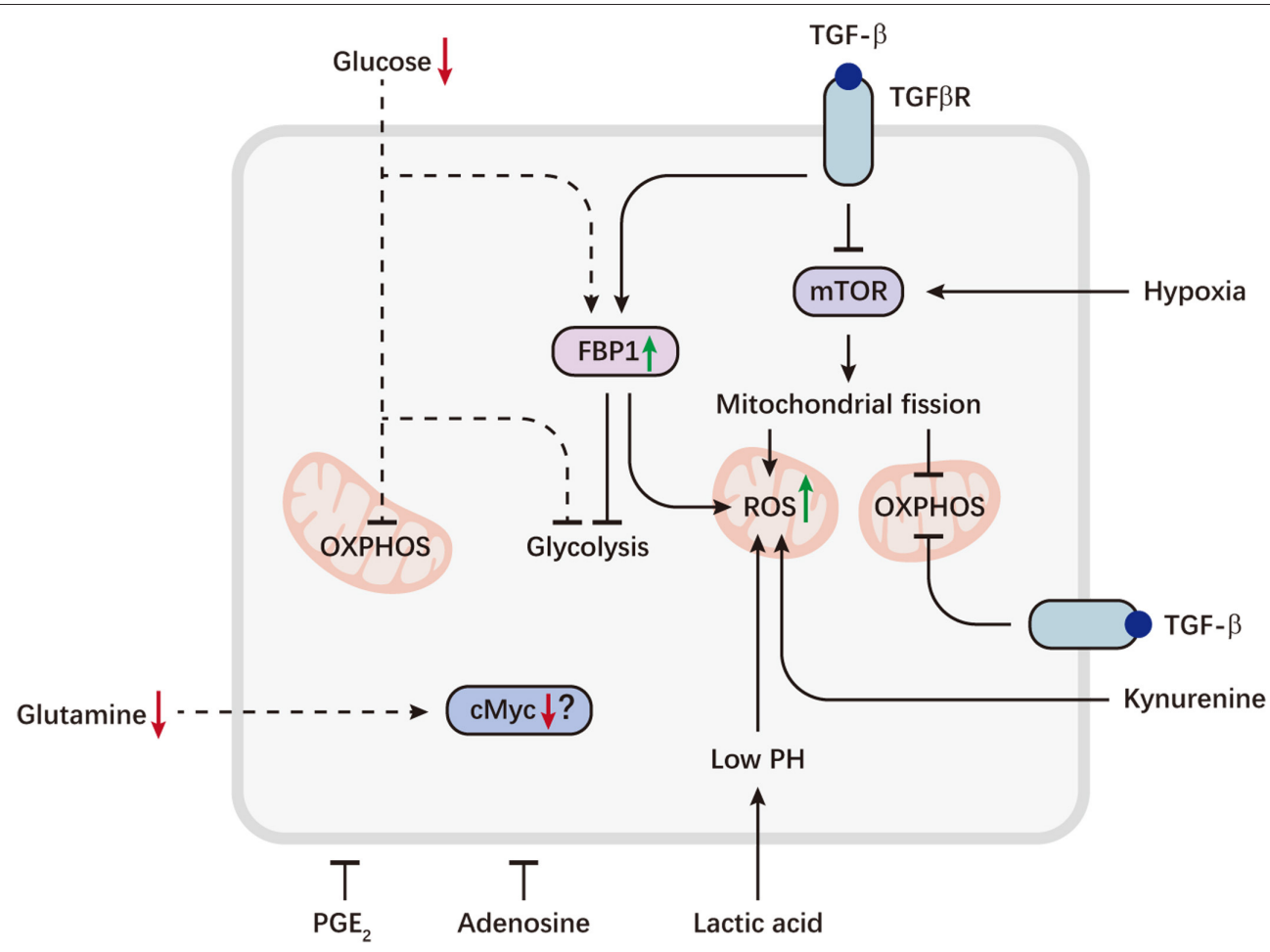

FIGURE 2 | Metabolic reprogramming of NK cells in the tumor microenvironment. Tumor cells can evade immunosurveillance by repressing NK cell metabolism. Aberrant expression of the gluconeogenic enzyme FBP1, caused by TGF $\beta$, can inhibit NK cell glycolysis and promote ROS production. TGF $\beta$ also directly inhibits mTOR and drives mitochondrial dysfunction. On the other hand, sustained activation of mTOR induced by hypoxia, can lead to excessive fragmentation of mitochondria via fission, which is associated with decreased OXPHOS and increased ROS levels. Tumor-imposed metabolic restrictions may be involved in NK cell dysfunction. Depletion of glucose, a key fuel for NK cells, may induce FBP1 expression or directly restrict glucose utilization by NK cells, resulting in defective glycolysis and OXPHOS. Decreased availability of glutamine may lead to a loss of cMyc protein, thereby inhibiting NK cell metabolism. Immunosuppressive metabolites accumulated in the tumor microenvironment, including lactic acid, kynurenine, PGE 2 and adenosine, are potent inhibitors of NK cell viability and effector functions. Lactic acid causes decreased ATP synthesis and intracellular acidification, resulting in accumulation of ROS. Kynurenine can also induce NK cell apoptosis via ROS. Dashed lines indicate likely (unproven) interactions.

cells exposed to persistent inflammation. This scenario results in deterioration of NK cell effector functions and is often accompanied by upregulation of inhibitory receptors, such as PD-1, NKG2A, and Tim-3, a status akin to $\mathrm{CD}^{+} \mathrm{T}$ cell exhaustion (106-109). Further, a recent study by Cubero et al. showed that, during chronic HIV-1 infection, NK cells exhibited metabolic defects bearing similarities to exhausted $\mathrm{CD} 8^{+} \mathrm{T}$ cells (110). Persistent HIV-1 infection led to NK cell mitochondrial dysfunction, characterized by defective OXPHOS, increased mitochondrial depolarization and fragmented mitochondria, which limited the ability of NK cells to mobilize alternative fuels to power IFN- $\gamma$ production upon activating receptor stimulation; a state of metabolic inflexibility. IL-15 pre-treatment could bypass the metabolic requirement of NK cells for receptor ligation and potentiate NK cell functions. Indeed, activation of NK cells by stimulation of activating receptors has been demonstrated to be an energy-demanding process (39, 110).

Recent research has linked the increased expression of inhibitory receptors to compromised cellular metabolism. For example, PD-1 represses glycolytic and mitochondrial metabolism via inhibiting the expression of a critical metabolic regulator, thereby exhausting $\mathrm{CD} 8^{+} \mathrm{T}$ cells (111). Another study identified a role of LAG-3 in limiting CD $4^{+} \mathrm{T}$ cell mitochondrial biogenesis (112). As multiple inhibitory receptors, including PD1, are upregulated on NK cells during chronic viral infection, they may also negatively regulate the metabolic fitness of NK cells.

\section{METABOLISM OF OTHER ILCS}

Like Th1 cells, ILC1s are non-cytotoxic innate helper lymphoid cells, which defend against intracellular pathogens through production of IFN- $\gamma$ and TNF. There is evidence that NK cells can be converted into ILC1s under pathological conditions, such as tumor growth, and TGF- $\beta$ is a critical driver (113, 114). The fact that TGF- $\beta$ has been demonstrated to regulate cellular metabolism suggests that metabolic reprogramming may be implicated in controlling the plasticity of group 1 ILCs $(36,115,116)$. Indeed, direct killing of abnormal target cells is an energy-demanding process, and ILC1s hardly possess such capacity $(35,114,117)$. In contrast, ILC1s in the tumor microenvironment exhibit increased TNF production, which is independent of mTOR and glycolytic 
pathways $(55,114)$. Furthermore, compared with tumor NK cells, tumor ILC1s express higher levels of the genes encoding PD-1 and LAG-3, which repress bioenergetics and mitochondrial biogenesis in $\mathrm{T}$ cells $(111,112,114)$. These findings indicate that low metabolic activity may be sufficient to support the requirements for ILC1 survival and function, and this confers them a survival advantage in the nutrientdeprived tumor microenvironment. However, in most cases, such as viral infection and inflammation, NK cells are not converted to ILC1s $(9,118-121)$, and the metabolic pathways used by such ILC1s to response to pathogens remain to be determined.

It is widely accepted that glycolysis is indispensable to fuel NK cell proliferation and effector functions, and emerging evidence suggests that glycolysis is also closely involved in the regulation ILC2s and ILC3s. Monticelli et al. found that ILC2s showed elevated glycolytic capacity in comparison to Th2 cells in response to IL-33, indicating that activated ILC2s have the potential to engage glycolysis (122); however, a shift in the balance of metabolism from OXPHOS toward increased glycolysis led to defective in ILC2 maturation and function $(123,124)$. These results imply that glycolysis may act as a rheostat that modulates ILC2 immune responses. Transcriptional analysis demonstrated that resting ILC3s are enriched for pathways associated with carbohydrate metabolism and glycolysis, consistent with the finding that mTOR is essential for the generation of ILC3s $(38,125)$. Moreover, ILC3s rely on mTOR-HIF1 $\alpha$ axis-induced glycolysis, as well as mitochondrial ROS, for proliferation and cytokine secretion after in vitro activation by IL- $1 \beta$ and IL-23 or during bacterial infection (126). Nevertheless, HIF1 $\alpha$ is not required to support increased glycolysis in activated NK cells (57). In addition to glucose metabolism, FA metabolism also plays an important role in ILC3 function. FAO contributes to the production of IL17 and IL-22 by ILC3s, and elevated FA uptake has been observed in activated ILC3s (126). FA synthesis is dispensable for survival and proliferation of ROR $\gamma \mathrm{t}^{+}$ILCs (ILC3s), but it promotes $\mathrm{ROR} \gamma \mathrm{t}^{+}$ILC-derived IL-22 expression during intestinal infection. Blockade of FA synthesis by targeting the key enzyme acetyl-CoA carboxylase 1 (ACC1) in these cells can dampen epithelial defense mechanisms by interfering with IL-22 production (127). In line with these findings, Di Luccia et al. also demostrated that FA synthesis is evident in activated ILC3s, which is a metabolic feature different from Th17 cells (126).

Recent studies have demonstrated the critical role of amino acid and FA metabolism in ILC2-mediated type 2 immune responses $(122,128)$. The metabolic enzyme arginase-1 (Arg1), which metabolizes L-arginine into urea and ornithine to yield a range of downstream metabolites critical for cellular and bioenergetic processes, is constitutively expressed in precursor and mature ILC2s (122). Deletion of ILC-intrinsic, but not myeloid cell-intrinsic, Arg1 restrains ILC2 responses and dampens type 2 inflammation in the lung (122). Mechanistically, Arg1 is required for optimal ILC2 proliferation and cytokine secretion, and inhibition of Arg1 prevents conversion of Larginine into polyamines, which can regulate cell growth and survival (122). Arg1 promotes the glycolytic capacity of activated ILC2s, but minimally influences their OXPHOS, indicating a role for Arg1 in the regulation of glucose metabolism. Although Arg1 is also expressed in a proportion of ILC3s, it is not required for ILC3 development and function (122).

Another study identified genes involved in FA metabolism as a metabolic feature of intestinal ILC2s and, accordingly, intestinal ILC2s constitutively acquire large amounts of extracellular FAs $(128,129)$. FAO is dispensable for ILC2 homeostasis; however, abrogation of FAO significantly impairs intestinal ILC2 accumulation and production of IL-5 and IL-13 during helminth infection (128). Nevertheless, blocking glucose utilization does not impact ILC2 accumulation and function, suggesting that ILC2s mainly generate energy by breaking down FAs for OXPHOS, to protect against helminth infection (128). In addition to intestinal ILC2s, FAO is also important for mediation of allergic inflammation by lung ILC2s (124). In the absence of vitamin $\mathrm{A}$ or its metabolite retinoic acid, there is an increase in the number and function of ILC2s, caused by their elevated FA uptake and enhanced FAO $(128,130)$. In contrast, vitamin A and retinoic acid promote intestinal ILC3 accumulation and function $(130,131)$. These findings are interesting, as lipids and vitamin A have different effects on NK cells, ILC2s, and ILC3s, suggesting that the distinct metabolic profiles of each type of ILC are coupled to their unique characteristics.

\section{TARGETING ILC METABOLISM FOR THERAPY}

Dysfunction of ILCs can lead to defective immunosurveillance or excessive inflammation, which are important causes of many diseases, and adjusting ILC function through manipulation of metabolism is a potential direction for therapy. There are several potential ways in which ILC metabolism could be targeted.

\section{Cell-Intrinsic Metabolic Regulators and Pathways}

As mentioned earlier, NK cell and non-NK ILC functions are controlled by a range of metabolic regulators and pathways. Inhibiting PPAR or blocking lipid transport into mitochondria restores NK cell cytotoxicity during obesity, which might improve cancer outcomes in such patients (35). Tumor-induced FBP1 and mitochondrial fragmentation account for impaired NK cell anti-tumor functions by compromising glycolysis and mitochondrial respiration, respectively, and targeting them can enhance NK cell-based tumor immunosurveillance (34, 37). Dysregulation of mTOR activity is observed in diverse tumors. mTOR signaling is excessive activated in tumor NK cells from patients with liver cancer, but is inhibited in peripheral blood NK cells from patients with metastatic breast cancer, and such aberrant mTOR activity is a critical driver of NK cell dysfunction $(36,37)$. Thus, mTOR activity modulation is another strategy that helps NK cells to achieve optimal function. As cMyc controls the expression of the metabolic machinery required for NK cell effector functions, 
therapeutic strategies that sustain $\mathrm{cMyc}$ protein levels, through inhibiting its degradation [by glycogen synthase kinase 3 (GSK3) blockade] or increasing glutamine availability (by glutaminase blockade), may contribute to improved immunosurveillance (57). Indeed, GSK3-inhibited NK cells show increased efficacy in multiple tumor models, although it remains unclear whether a metabolism-related mechanism is involved $(132,133)$. For ILC2-mediated type 2 immune inflammation, modulation of Argl enzymatic activity and fuel dependency are potentially new therapeutic approaches.

\section{Cytokines and Metabolites}

TGF- $\beta$ represses NK cells through multiple mechanisms, suggesting that blocking the interaction between NK cells and TGF- $\beta$ could be a promising approach for protecting the metabolism and functions of NK cells in TGF- $\beta$ rich environments, such as cancers. Recent studies found that NK cells genetically modified with a dominant-negative TGF- $\beta$ receptor II resisted the suppressive effect of TGF$\beta$ and retained their potent ability to kill glioblastoma and breast tumor cells $(134,135)$. Such modified NK cells may also have improved metabolic parameters, as another study showed that blocking TGF- $\beta$ ex vivo using neutralizing antibody restored the effector function and mitochondrial metabolism of NK cells from patients with metastatic breast cancer (36). In addition to TGF- $\beta$, there are soluble immunosuppressive metabolites, such as lactic acid, kynurenine and $\mathrm{PGE}_{2}$, in tumor microenvironments; therapeutic strategies that target these metabolites, through inhibition of lactate dehydrogenase, indoleamine 2,3-dioxygenases, and cyclooxygenase 2, respectively, may invigorate NK cell-based tumor immunosurveillance $(99,136,137)$.

On the other hand, IL-15 priming has been demonstrated to reduce NK cell reliance on cellular metabolism, hence, IL15 agonists may be effective for enhancing NK cell function in metabolically challenging environments, including viral infections and cancers $(67,110)$.

\section{Immune Checkpoints}

Emerging immune checkpoint blockade strategies are being tested for their potential to reverse NK cell dysfunction in cancer and chronic viral infections, and there is evidence that anti-PD-1 or anti-PD-L1 antibody can enhance the anti-tumor efficacy of NK cells in multiple tumor models $(138,139)$. Given that the positive effects of PD1/PD-L1 blockade on $\mathrm{T}$ cells are partly attributable to restoration of glycolytic and mitochondrial metabolism (111), this metabolism-related mechanism may also be involved in the reversal of NK cell dysfunction by checkpoint blockade.

\section{CONCLUDING REMARKS}

Although the importance of cellular metabolism for immune function has been well-documented, the study of ILC metabolism is newly emerging. Over the past decade, evidence has mounted that cellular metabolism supports many aspects of the biology of NK cells and other ILCs, and that metabolic changes can dominate their immune responses; however, several major issues remain to be solved, including: (i) ILCs are the innate counterparts of T cells, and ILC1s mirror Th1 cells. Given the importance of metabolism in the survival and functions of $\mathrm{T}$ cells including Th1 cells, it will be interesting to investigate the major metabolic pathways utilized by ILC1s as well as LTi cells in the context of homeostasis and disorders. (ii) ILC plasticity has been demonstrated to be essential to shape ILC responses to diverse stimuli $(113,114,140)$, which confers ILC subsets the capacities to change their phenotype and functions under specific circumstances, but nothing is known about the authentic metabolic alterations required for ILC plasticity. (iii) Recent findings show that functions of NK cells are markedly influenced by their local microenvironments, and that the unique characteristics of NK cells in different tissues have been uncovered step by step $(141,142)$. Other ILCs are largely tissue-resident cells, and this tissue dwelling property and the specialized distribution of non-NK ILCs are coupled to their functional heterogeneity (1). However, what are the differences in the metabolism of ILCs from diverse tissues, and how ILC metabolism is shaped by tissue microenvironments remains unclear at present. (iv) Whether and how intrinsic metabolism controls the circulating and tissue-resident characteristics of ILCs? (v) In addition to immune defense, NK cells can mediate immune tolerance and immune regulation; for example, promoting positive pregnancy outcomes through the secretion of growth-promoting factors, angiogenesis-regulating molecules, and cytokines, or maintaining liver immunotolerance through the regulation of dendritic cell-mediated tolerogenic regulatory $\mathrm{T}$ cell induction (143-147). However, how metabolic regulation is involved in immune tolerance and immune regulation mediated by $\mathrm{NK}$ cells, and the role of metabolism in controlling $\mathrm{NK}$ cell function switch, remains to be determined. (vi) How NK cell metabolism is involved in other diseases, in which NK cell abnormalities have been demonstrated, such as allergy and autoinflammatory diseases? A more thorough understanding of ILC metabolism will provide deep insights into ILC biology and aid the development of effective therapeutic strategies based on ILCs.

\section{AUTHOR CONTRIBUTIONS}

JC designed the review, wrote, and revised the manuscript.

\section{FUNDING}

This work was supported by the key project of the National Natural Science Foundation of China (81902908), Postdoctoral Innovative Talent Support Program, and China Postdoctoral Science Foundation (2019M662204). 


\section{REFERENCES}

1. Spits H, Artis D, Colonna M, Diefenbach A, Di Santo JP, Eberl G, et al. Innate lymphoid cells-a proposal for uniform nomenclature. Nat Rev Immunol. (2013) 13:145-9. doi: 10.1038/nri3365

2. Artis D, Spits H. The biology of innate lymphoid cells. Nature. (2015) 517:293-301. doi: 10.1038/nature14189

3. Serafini N, Vosshenrich CA, Di Santo JP. Transcriptional regulation of innate lymphoid cell fate. Nat Rev Immunol. (2015) 15:415-28. doi: 10.1038/nri3855

4. Vivier E, Artis D, Colonna M, Diefenbach A, Di Santo JP, Eberl G, et al. Innate lymphoid cells: 10 years on. Cell. (2018) 174:1054-66. doi: 10.1016/j.cell.2018.07.017

5. Kansler ER, Li MO. Innate lymphocytes-lineage, localization and timing of differentiation. Cell Mol Immunol. (2019) 16:627-33. doi: 10.1038/s41423-019-0211-7

6. Vivier E, Tomasello E, Baratin M, Walzer T, Ugolini S. Functions of natural killer cells. Nat Immunol. (2008) 9:503-10. doi: 10.1038/ni1582

7. Fuchs A, Vermi W, Lee JS, Lonardi S, Gilfillan S, Newberry RD, et al. Intraepithelial type 1 innate lymphoid cells are a unique subset of IL-12- and IL-15-responsive IFN-gamma-producing cells. Immunity. (2013) 38:769-81. doi: 10.1016/j.immuni.2013.02.010

8. Klose CSN, Flach M, Mohle L, Rogell L, Hoyler T, Ebert K, et al. Differentiation of type 1 ILCs from a common progenitor to all helper-like innate lymphoid cell lineages. Cell. (2014) 157:340-56. doi: 10.1016/j.cell.2014.03.030

9. Weizman OE, Adams NM, Schuster IS, Krishna C, Pritykin Y, Lau C, et al. ILC1 confer early host protection at initial sites of viral infection. Cell. (2017) 171:795-808.e712. doi: 10.1016/j.cell.2017.09.052

10. Moro K, Yamada T, Tanabe M, Takeuchi T, Ikawa T, Kawamoto H, et al. Innate production of $\mathrm{T}(\mathrm{H}) 2$ cytokines by adipose tissueassociated c-Kit(+)Sca-1(+) lymphoid cells. Nature. (2010) 463:540-4. doi: $10.1038 /$ nature 08636

11. Neill DR, Wong SH, Bellosi A, Flynn RJ, Daly M, Langford TK, et al. Nuocytes represent a new innate effector leukocyte that mediates type-2 immunity. Nature. (2010) 464:1367-70. doi: 10.1038/nature08900

12. Mjosberg JM, Trifari S, Crellin NK, Peters CP, van Drunen CM, Piet B, et al. Human IL-25- and IL-33-responsive type 2 innate lymphoid cells are defined by expression of CRTH2 and CD161. Nat Immunol. (2011) 12:1055-62. doi: $10.1038 /$ ni.2104

13. Monticelli LA, Sonnenberg GF, Abt MC, Alenghat T, Ziegler CG, Doering TA, et al. Innate lymphoid cells promote lung-tissue homeostasis after infection with influenza virus. Nat Immunol. (2011) 12:1045-54. doi: $10.1038 /$ ni.2131

14. Gurram RK, Zhu J. Orchestration between ILC2s and Th2 cells in shaping type 2 immune responses. Cell Mol Immunol. (2019) 16:225-35. doi: 10.1038/s41423-019-0210-8

15. Satoh-Takayama N, Vosshenrich CA, Lesjean-Pottier S, Sawa S, Lochner M, Rattis F, et al. Microbial flora drives interleukin 22 production in intestinal $\mathrm{NKp} 46+$ cells that provide innate mucosal immune defense. Immunity. (2008) 29:958-70. doi: 10.1016/j.immuni.2008.11.001

16. Cella M, Fuchs A, Vermi W, Facchetti F, Otero K, Lennerz JK, et al. A human natural killer cell subset provides an innate source of IL-22 for mucosal immunity. Nature. (2009) 457:722-5. doi: 10.1038/nature07537

17. Cupedo T, Crellin NK, Papazian N, Rombouts EJ, Weijer K, Grogan JL, et al. Human fetal lymphoid tissue-inducer cells are interleukin 17-producing precursors to RORC+CD127+ natural killer-like cells. Nat Immunol. (2009) 10:66-74. doi: 10.1038/ni.1668

18. Luci C, Reynders A, Ivanov II, Cognet C, Chiche L, Chasson L, et al. Influence of the transcription factor RORgammat on the development of NKp46+ cell populations in gut and skin. Nat Immunol. (2009) 10:75-82. doi: $10.1038 /$ ni.1681

19. Mebius RE, Rennert P, Weissman IL. Developing lymph nodes collect CD4+CD3- LTbeta+ cells that can differentiate to APC, NK cells, and follicular cells but not T or B cells. Immunity. (1997) 7:493-504. doi: 10.1016/S1074-7613(00)80371-4

20. O'Leary JG, Goodarzi M, Drayton DL, von Andrian UH. T cell- and B cell-independent adaptive immunity mediated by natural killer cells. Nat Immunol. (2006) 7:507-16. doi: 10.1038/ni1332
21. Cooper MA, Elliott JM, Keyel PA, Yang L, Carrero JA, Yokoyama WM. Cytokine-induced memory-like natural killer cells. Proc Natl Acad Sci USA. (2009) 106:1915-9. doi: 10.1073/pnas.0813192106

22. Sun JC, Beilke JN, Lanier LL. Adaptive immune features of natural killer cells. Nature. (2009) 457:557-61. doi: 10.1038/nature07665

23. Wang X, Peng H, Tian Z. Innate lymphoid cell memory. Cell Mol Immunol. (2019) 16:423-9. doi: 10.1038/s41423-019-0212-6

24. Wang $X$, Tian $Z$, Peng $H$. Tissue-resident memory-like ILCs: innate counterparts of TRM cells. Protein Cell. (2020) 11:85-96. doi: 10.1007/s13238-019-0647-7

25. O’Neill LA, Kishton RJ, Rathmell J. A guide to immunometabolism for immunologists. Nat Rev Immunol. (2016) 16:553-65. doi: $10.1038 /$ nri.2016.70

26. Truswell S. Metabolism at a glance. Third edition. In: Nutrition \& Dietetics: The Journal of the Dietitians Association of Australia. Vol. 62 (2005). p. 56.

27. Wang T, Marquardt C, Foker J. Aerobic glycolysis during lymphocyte proliferation. Nature. (1976) 261:702-5. doi: 10.1038/261702a0

28. Vander Heiden MG, Cantley LC, Thompson CB. Understanding the Warburg effect: the metabolic requirements of cell proliferation. Science. (2009) 324:1029-33. doi: 10.1126/science.1160809

29. Hotamisligil GS. Foundations of immunometabolism and implications for metabolic health and disease. Immunity. (2017) 47:406-20. doi: 10.1016/j.immuni.2017.08.009

30. O’Sullivan TE, Sun JC. Innate lymphoid cell immunometabolism. J Mol Biol. (2017) 429:3577-86. doi: 10.1016/j.jmb.2017.08.014

31. Wilhelm C, Kharabi Masouleh S, Kazakov A. Metabolic regulation of innate lymphoid cell-mediated tissue protection-linking the nutritional state to barrier immunity. Front Immunol. (2017) 8:1742. doi: 10.3389/fimmu.2017.01742

32. Gardiner CM. NK cell metabolism. J Leukoc Biol. (2019) 105:1235-42. doi: 10.1002/JLB.MR0718-260R

33. O'Brien KL, Finlay DK. Immunometabolism and natural killer cell responses. Nat Rev Immunol. (2019) 19:282-90. doi: 10.1038/s41577-019-0139-2

34. Cong J, Wang X, Zheng X, Wang D, Fu B, Sun R, et al. Dysfunction of natural killer cells by FBP1-induced inhibition of glycolysis during lung cancer progression. Cell Metab. (2018) 28:243-55.e245. doi: 10.1016/j.cmet.2018.06.021

35. Michelet X, Dyck L, Hogan A, Loftus RM, Duquette D, Wei K, et al. Metabolic reprogramming of natural killer cells in obesity limits antitumor responses. Nat Immunol. (2018) 19:1330-40. doi: 10.1038/s41590-018-0251-7

36. Slattery K, Zaiatz-Bittencourt V, Woods E, Brennan K, Marks S, Chew S, et al. TGF $\beta$ drives mitochondrial dysfunction in peripheral blood NK cells during metastatic breast cancer. bioRxiv. (2019) 1:648501. doi: 10.1101/64 8501

37. Zheng X, Qian Y, Fu B, Jiao D, Jiang Y, Chen P, et al. Mitochondrial fragmentation limits NK cell-based tumor immunosurveillance. Nat Immunol. (2019) 20:1656-67. doi: 10.1038/s41590-019-0511-1

38. Marcais A, Cherfils-Vicini J, Viant C, Degouve S, Viel S, Fenis A, et al. The metabolic checkpoint kinase mTOR is essential for IL-15 signaling during the development and activation of NK cells. Nat Immunol. (2014) 15:749-57. doi: 10.1038/ni.2936

39. Keppel MP, Saucier N, Mah AY, Vogel TP, Cooper MA. Activation-specific metabolic requirements for NK Cell IFN-gamma production. J Immunol. (2015) 194:1954-62. doi: 10.4049/jimmunol.1402099

40. Keating SE, Zaiatz-Bittencourt V, Loftus RM, Keane C, Brennan K, Finlay DK, et al. Metabolic reprogramming supports IFN-gamma production by CD56bright NK cells. J Immunol. (2016) 196:2552-60. doi: 10.4049/jimmunol.1501783

41. Lanier LL, Le AM, Civin CI, Loken MR, Phillips JH. The relationship of CD16 (Leu-11) and Leu-19 (NKH-1) antigen expression on human peripheral blood NK cells and cytotoxic $\mathrm{T}$ lymphocytes. I Immunol. (1986) 136:4480-6.

42. Cooper MA, Fehniger TA, Turner SC, Chen KS, Ghaheri BA, Ghayur T, et al. Human natural killer cells: a unique innate immunoregulatory role for the CD56 (bright) subset. Blood. (2001) 97:3146-51. doi: 10.1182/blood.V97.10.3146 
43. Fauriat C, Long EO, Ljunggren HG, Bryceson YT. Regulation of human NKcell cytokine and chemokine production by target cell recognition. Blood. (2010) 115:2167-76. doi: 10.1182/blood-2009-08-238469

44. Sivori S, Vacca P, Del Zotto G, Munari E, Mingari MC, Moretta L. Human NK cells: surface receptors, inhibitory checkpoints, and translational applications. Cell Mol Immunol. (2019) 16:430-41. doi: 10.1038/s41423-019-0206-4

45. Salzberger W, Martrus G, Bachmann K, Goebels H, Hess L, Koch M, et al. Tissue-resident NK cells differ in their expression profile of the nutrient transporters Glut1, CD98 and CD71. PLoS ONE. (2018) 13:e0201170. doi: 10.1371/journal.pone. 0201170

46. Kim S, Iizuka K, Kang HS, Dokun A, French AR, Greco S, et al. In vivo developmental stages in murine natural killer cell maturation. Nat Immunol. (2002) 3:523-8. doi: 10.1038/ni796

47. Hayakawa Y, Huntington ND, Nutt SL, Smyth MJ. Functional subsets of mouse natural killer cells. Immunol Rev. (2006) 214:47-55. doi: 10.1111/j.1600-065X.2006.00454.x

48. Hayakawa Y, Smyth MJ. CD27 dissects mature NK cells into two subsets with distinct responsiveness and migratory capacity. J Immunol. (2006) 176:1517-24. doi: 10.4049/jimmunol.176.3.1517

49. Chiossone L, Chaix J, Fuseri N, Roth C, Vivier E, Walzer T. Maturation of mouse NK cells is a 4-stage developmental program. Blood. (2009) 113:548896. doi: 10.1182/blood-2008-10-187179

50. Kim S, Poursine-Laurent J, Truscott SM, Lybarger L, Song YJ, Yang L, et al. Licensing of natural killer cells by host major histocompatibility complex class I molecules. Nature. (2005) 436:709-13. doi: 10.1038/nature03847

51. Anfossi N, Andre P, Guia S, Falk CS, Roetynck S, Stewart CA, et al. Human NK cell education by inhibitory receptors for MHC class I. Immunity. (2006) 25:331-42. doi: 10.1016/j.immuni.2006.06.013

52. Schafer JR, Salzillo TC, Chakravarti N, Kararoudi MN, Trikha P, Foltz JA, et al. Education-dependent activation of glycolysis promotes the cytolytic potency of licensed human natural killer cells. J Allergy Clin Immunol. (2019) 143:346-58.e346. doi: 10.1016/j.jaci.2018.06.047

53. Marcais A, Marotel M, Degouve S, Koenig A, Fauteux-Daniel S, Drouillard A, et al. High mTOR activity is a hallmark of reactive natural killer cells and amplifies early signaling through activating receptors. Elife. (2017) 6:e26423. doi: $10.7554 /$ eLife.26423.022

54. Mossmann D, Park S, Hall MN. mTOR signalling and cellular metabolism are mutual determinants in cancer. Nat Rev Cancer. (2018) 18:744-57. doi: 10.1038/s41568-018-0074-8

55. Donnelly RP, Loftus RM, Keating SE, Liou KT, Biron CA, Gardiner $\mathrm{CM}$, et al. mTORC1-dependent metabolic reprogramming is a prerequisite for NK cell effector function. J Immunol. (2014) 193:4477-84. doi: $10.4049 /$ jimmunol.1401558

56. Assmann N, O'Brien KL, Donnelly RP, Dyck L, Zaiatz-Bittencourt V, Loftus RM, et al. Srebp-controlled glucose metabolism is essential for NK cell functional responses. Nat Immunol. (2017) 18:1197-206. doi: $10.1038 /$ ni.3838

57. Loftus RM, Assmann N, Kedia-Mehta N, O’Brien KL, Garcia A, Gillespie $\mathrm{C}$, et al. Amino acid-dependent cMyc expression is essential for NK cell metabolic and functional responses in mice. Nat Commun. (2018) 9:2341. doi: 10.1038/s41467-018-04719-2

58. Buck MD, O'Sullivan D, Pearce EL. T cell metabolism drives immunity. J Exp Med. (2015) 212:1345-60. doi: 10.1084/jem.20151159

59. Vitale I, Manic G, Coussens LM, Kroemer G, Galluzzi L. Macrophages and metabolism in the tumor microenvironment. Cell Metab. (2019) 30:36-50. doi: 10.1016/j.cmet.2019.06.001

60. Long EO, Kim HS, Liu D, Peterson ME, Rajagopalan S. Controlling natural killer cell responses: integration of signals for activation and inhibition. Annu Rev Immunol. (2013) 31:227-58. doi: 10.1146/annurev-immunol-020711-075005

61. Kidani Y, Elsaesser H, Hock MB, Vergnes L, Williams KJ, Argus JP, et al. Sterol regulatory element-binding proteins are essential for the metabolic programming of effector $\mathrm{T}$ cells and adaptive immunity. Nat Immunol. (2013) 14:489-99. doi: 10.1038/ni.2570

62. Berod L, Friedrich C, Nandan A, Freitag J, Hagemann S, Harmrolfs K, et al. De novo fatty acid synthesis controls the fate between regulatory $\mathrm{T}$ and $\mathrm{T}$ helper 17 cells. Nat Med. (2014) 20:1327-33. doi: 10.1038/nm.3704
63. Fehniger TA, Cai SF, Cao X, Bredemeyer AJ, Presti RM, French AR, et al. Acquisition of murine NK cell cytotoxicity requires the translation of a pre-existing pool of granzyme B and perforin mRNAs. Immunity. (2007) 26:798-811. doi: 10.1016/j.immuni.2007.04.010

64. Orr SJ, Roessler S, Quigley L, Chan T, Ford JW, O'Connor GM, et al. Implications for gene therapy-limiting expression of IL-2R gamma $c$ delineate differences in signaling thresholds required for lymphocyte development and maintenance. J Immunol. (2010) 185:1393-403. doi: 10.4049/jimmunol.0903528

65. Lee GA, Liou YH, Wang SW, Ko KL, Jiang ST, Liao NS. Different NK cell developmental events require different levels of IL-15 trans-presentation. $J$ Immunol. (2011) 187:1212-21. doi: 10.4049/jimmunol.1100331

66. Felices M, Lenvik AJ, McElmurry R, Chu S, Hinderlie P, Bendzick L, et al. Continuous treatment with IL-15 exhausts human NK cells via a metabolic defect. JCI Insight. (2018) 3:e96219. doi: 10.1172/jci.insight.96219

67. Mah AY, Rashidi A, Keppel MP, Saucier N, Moore EK, Alinger JB, et al. Glycolytic requirement for NK cell cytotoxicity and cytomegalovirus control. JCI Insight. (2017) 2:e95128. doi: 10.1172/jci.insight.95128

68. O'Sullivan TE, Johnson LR, Kang HH, Sun JC. BNIP3- and BNIP3Lmediated mitophagy promotes the generation of natural killer cell memory. Immunity. (2015) 43:331-42. doi: 10.1016/j.immuni.2015.07.012

69. Pearce EL, Walsh MC, Cejas PJ, Harms GM, Shen H, Wang LS, et al. Enhancing CD8 T-cell memory by modulating fatty acid metabolism. Nature. (2009) 460:103-7. doi: 10.1038/nature08097

70. van der Windt GJ, Everts B, Chang CH, Curtis JD, Freitas TC, Amiel E, et al. Mitochondrial respiratory capacity is a critical regulator of CD8+ T cell memory development. Immunity. (2012) 36:68-78. doi: 10.1016/j.immuni.2011.12.007

71. Xu X, Araki K, Li S, Han JH, Ye L, Tan WG, et al. Autophagy is essential for effector CD8(+) T cell survival and memory formation. Nat Immunol. (2014) 15:1152-61. doi: 10.1038/ni.3025

72. Guma M, Angulo A, Vilches C, Gomez-Lozano N, Malats N, Lopez-Botet M. Imprint of human cytomegalovirus infection on the NK cell receptor repertoire. Blood. (2004) 104:3664-71. doi: 10.1182/blood-2004-05-2058

73. Lopez-Verges S, Milush JM, Schwartz BS, Pando MJ, Jarjoura J, York VA, et al. Expansion of a unique CD57(+)NKG2Chi natural killer cell subset during acute human cytomegalovirus infection. Proc Natl Acad Sci USA. (2011) 108:14725-32. doi: 10.1073/pnas.1110900108

74. Foley B, Cooley S, Verneris MR, Pitt M, Curtsinger J, Luo X, et al. Cytomegalovirus reactivation after allogeneic transplantation promotes a lasting increase in educated NKG2C+ natural killer cells with potent function. Blood. (2012) 119:2665-74. doi: 10.1182/blood-2011-10-38 6995

75. Cichocki F, Wu CY, Zhang B, Felices M, Tesi B, Tuininga K, et al. ARID5B regulates metabolic programming in human adaptive NK cells. J Exp Med. (2018) 215:2379-95. doi: 10.1084/jem.20172168

76. Li T, Wang J, Wang Y, Chen Y, Wei H, Sun R, et al. Respiratory influenza virus infection induces memory-like liver NK cells in mice. J Immunol. (2017) 198:1242-52. doi: 10.4049/jimmunol.1502186

77. Wang X, Peng H, Cong J, Wang X, Lian Z, Wei H, et al. Memory formation and long-term maintenance of IL-7Ralpha(+) ILC1s via a lymph node-liver axis. Nat Commun. (2018) 9:4854. doi: 10.1038/s41467-018-07 405-5

78. Calle EE, Kaaks R. Overweight, obesity and cancer: epidemiological evidence and proposed mechanisms. Nat Rev Cancer. (2004) 4:579-91. doi: $10.1038 / \mathrm{nrc1} 108$

79. Falagas ME, Kompoti M. Obesity and infection. Lancet Infect Dis. (2006) 6:438-46. doi: 10.1016/S1473-3099(06)70523-0

80. Renehan AG, Tyson M, Egger M, Heller RF, Zwahlen M. Bodymass index and incidence of cancer: a systematic review and metaanalysis of prospective observational studies. Lancet. (2008) 371:569-78. doi: 10.1016/S0140-6736(08)60269-X

81. Tobin LM, Mavinkurve M, Carolan E, Kinlen D, O'Brien EC, Little MA, et al. NK cells in childhood obesity are activated, metabolically stressed, and functionally deficient. JCI Insight. (2017) 2:e94939. doi: 10.1172 /jci.insight.94939

82. O'Shea D, Hogan AE. Dysregulation of natural killer cells in obesity. Cancers. (2019) 11:573. doi: 10.3390/cancers 11040573 
83. Wensveen FM, Jelencic V, Valentic S, Sestan M, Wensveen TT, Theurich S, et al. NK cells link obesity-induced adipose stress to inflammation and insulin resistance. Nat Immunol. (2015) 16:376-85. doi: 10.1038/ni.3120

84. Lee BC, Kim MS, Pae M, Yamamoto Y, Eberle D, Shimada T, et al. Adipose natural killer cells regulate adipose tissue macrophages to promote insulin resistance in obesity. Cell Metab. (2016) 23:685-98. doi: 10.1016/j.cmet.2016.03.002

85. O'Sullivan TE, Rapp M, Fan X, Weizman OE, Bhardwaj P, Adams $\mathrm{NM}$, et al. Adipose-resident group 1 innate lymphoid cells promote obesity-associated insulin resistance. Immunity. (2016) 45:428-41. doi: 10.1016/j.immuni.2016.06.016

86. Wang H, Shen L, Sun X, Liu F, Feng W, Jiang C, et al. Adipose group 1 innate lymphoid cells promote adipose tissue fibrosis and diabetes in obesity. Nat Commun. (2019) 10:3254. doi: 10.1038/s41467-019-11270-1

87. Platonova S, Cherfils-Vicini J, Damotte D, Crozet L, Vieillard V, Validire $\mathrm{P}$, et al. Profound coordinated alterations of intratumoral NK cell phenotype and function in lung carcinoma. Cancer Res. (2011) 71:5412-22. doi: 10.1158/0008-5472.CAN-10-4179

88. Pasero C, Gravis G, Guerin M, Granjeaud S, Thomassin-Piana J, Rocchi $\mathrm{P}$, et al. Inherent and tumor-driven immune tolerance in the prostate microenvironment impairs natural killer cell antitumor activity. Cancer Res. (2016) 76:2153-65. doi: 10.1158/0008-5472.CAN-15-1965

89. Habif G, Crinier A, André P, Vivier E, Narni-Mancinelli E. Targeting natural killer cells in solid tumors. Cell Mol Immunol. (2019) 16:415-22. doi: 10.1038/s41423-019-0224-2

90. Harmon C, Robinson MW, Hand F, Almuaili D, Mentor K, Houlihan $\mathrm{DD}$, et al. Lactate-mediated acidification of tumor microenvironment induces apoptosis of liver-resident NK cells in colorectal liver metastasis. Cancer Immunol Res. (2019) 7:335-46. doi: 10.1158/2326-6066.CIR-180481

91. Huang Q, Huang M, Meng F, Sun R. Activated pancreatic stellate cells inhibit NK cell function in the human pancreatic cancer microenvironment. Cell Mol Immunol. (2019) 16:87-9. doi: 10.1038/s41423-018-0014-2

92. Slattery K, Gardiner CM. NK cell metabolism and TGFbeta implications for immunotherapy. Front Immunol. (2019) 10:2915. doi: 10.3389/fimmu.2019.02915

93. Hensley CT, Wasti AT, DeBerardinis RJ. Glutamine and cancer: cell biology, physiology, and clinical opportunities. J Clin Invest. (2013) 123:3678-84. doi: 10.1172/JCI69600

94. Chang CH, Qiu J, O'Sullivan D, Buck MD, Noguchi T, Curtis JD, et al. Metabolic competition in the tumor microenvironment is a driver of cancer progression. Cell. (2015) 162:1229-41. doi: 10.1016/j.cell.2015.08.016

95. Nakazawa MS, Keith B, Simon MC. Oxygen availability and metabolic adaptations. Nat Rev Cancer. (2016) 16:663-73. doi: 10.1038/nrc.2016.84

96. Lyssiotis CA, Kimmelman AC. Metabolic interactions in the tumor microenvironment. Trends Cell Biol. (2017) 27:863-75. doi: 10.1016/j.tcb.2017.06.003

97. Huang L, Xu H, Peng G. TLR-mediated metabolic reprogramming in the tumor microenvironment: potential novel strategies for cancer immunotherapy. Cell Mol Immunol. (2018) 15:428-37. doi: $10.1038 / \mathrm{cmi} .2018 .4$

98. Husain Z, Huang Y, Seth P, Sukhatme VP. Tumor-derived lactate modifies antitumor immune response: effect on myeloid-derived suppressor cells and NK cells. J Immunol. (2013) 191:1486-95. doi: 10.4049/jimmunol.1202702

99. Brand A, Singer K, Koehl GE, Kolitzus M, Schoenhammer G, Thiel A, et al. LDHA-associated lactic acid production blunts tumor immunosurveillance by $\mathrm{T}$ and NK cells. Cell Metab. (2016) 24:657-71. doi: 10.1016/j.cmet.2016.08.011

100. Pötzl J, Roser D, Bankel L, Hömberg N, Geishauser A, Brenner CD, et al. Reversal of tumor acidosis by systemic buffering reactivates NK cells to express IFN- $\gamma$ and induces NK cell-dependent lymphoma control without other immunotherapies. Int J Cancer. (2017) 140:2125-33. doi: $10.1002 / \mathrm{ijc} .30646$

101. Della Chiesa M, Carlomagno S, Frumento G, Balsamo M, Cantoni C, Conte R, et al. The tryptophan catabolite L-kynurenine inhibits the surface expression of NKp46- and NKG2D-activating receptors and regulates NK-cell function. Blood. (2006) 108:4118-25. doi: 10.1182/blood-2006-03-006700
102. Song H, Park H, Kim YS, Kim KD, Lee HK, Cho DH, et al. L-kynurenineinduced apoptosis in human NK cells is mediated by reactive oxygen species. Int Immunopharmacol. (2011) 11:932-8. doi: 10.1016/j.intimp.2011.02.005

103. Li T, Zhang Q, Jiang Y, Yu J, Hu Y, Mou T, et al. Gastric cancer cells inhibit natural killer cell proliferation and induce apoptosis via prostaglandin E2. Oncoimmunology. (2016) 5:e1069936. doi: 10.1080/2162402X.2015.1069936

104. Böttcher JP, Bonavita E, Chakravarty P, Blees H, Cabeza-Cabrerizo M, Sammicheli S, et al. NK cells stimulate recruitment of cDC1 into the tumor microenvironment promoting cancer immune control. Cell. (2018) 172:1022-37.e1014. doi: 10.1016/j.cell.2018.01.004

105. Young A, Ngiow SF, Gao Y, Patch AM, Barkauskas DS, Messaoudene $\mathrm{M}$, et al. A2AR adenosine signaling suppresses natural killer cell maturation in the tumor microenvironment. Cancer Res. (2018) 78:1003-16. doi: 10.1158/0008-5472.CAN-17-2826

106. Ju Y, Hou N, Meng J, Wang X, Zhang X, Zhao D, et al. T cell immunoglobulin- and mucin-domain-containing molecule-3 (Tim-3) mediates natural killer cell suppression in chronic hepatitis B. J Hepatol. (2010) 52:322-9. doi: 10.1016/j.jhep.2009.12.005

107. Norris S, Coleman A, Kuri-Cervantes L, Bower M, Nelson M, Goodier MR. PD-1 expression on natural killer cells and CD8(+) T cells during chronic HIV-1 infection. Viral Immunol. (2012) 25:329-32. doi: 10.1089/vim.2011.0096

108. Li F, Wei H, Wei H, Gao Y, Xu L, Yin W, et al. Blocking the natural killer cell inhibitory receptor NKG2A increases activity of human natural killer cells and clears hepatitis B virus infection in mice. Gastroenterology. (2013) 144:392-401. doi: 10.1053/j.gastro.2012.10.039

109. Vitallé J, Terrén I, Orrantia A, Pérez-Garay R, Vidal F, Iribarren JA, et al. CD300a inhibits CD16-mediated NK cell effector functions in HIV-1-infected patients. Cell Mol Immunol. (2019) 16:940-2. doi: 10.1038/s41423-019-0275-4

110. Cubero EM, Balint S, Alrubayyi A, Ogbe A, Matthews R, Burns F, et al. IL15 re-programming compensates for NK cell mitochondrial dysfunction in HIV-1 infection. bioRxiv [Preprint]. (2019) 811117. doi: 10.1101/811117

111. Bengsch B, Johnson AL, Kurachi M, Odorizzi PM, Pauken KE, Attanasio J, et al. Bioenergetic insufficiencies due to metabolic alterations regulated by the inhibitory receptor PD-1 are an early driver of $\mathrm{CD} 8(+) \mathrm{T}$ cell exhaustion. Immunity. (2016) 45:358-73. doi: 10.1016/j.immuni.2016.07.008

112. Previte DM, Martins CP, O'Connor EC, Marre ML, Coudriet GM, Beck $\mathrm{NW}$, et al. Lymphocyte activation gene-3 maintains mitochondrial and metabolic quiescence in naive CD4(+) T cells. Cell Rep. (2019) 27:12941.e124. doi: 10.1016/j.celrep.2019.03.004

113. Cortez VS, Ulland TK, Cervantes-Barragan L, Bando JK, Robinette ML, Wang Q, et al. SMAD4 impedes the conversion of NK cells into ILC1-like cells by curtailing non-canonical TGF-beta signaling. Nat Immunol. (2017) 18:995-1003. doi: 10.1038/ni.3809

114. Gao Y, Souza-Fonseca-Guimaraes F, Bald T, Ng SS, Young A, Ngiow SF, et al. Tumor immunoevasion by the conversion of effector NK cells into type 1 innate lymphoid cells. Nat Immunol. (2017) 18:1004-15. doi: 10.1038/ni.3800

115. Viel S, Marcais A, Guimaraes FS, Loftus R, Rabilloud J, Grau M, et al. TGFbeta inhibits the activation and functions of NK cells by repressing the mTOR pathway. Sci Signal. (2016) 9:ra19. doi: 10.1126/scisignal.aad1884

116. Zaiatz-Bittencourt V, Finlay DK, Gardiner CM. Canonical TGF-beta signaling pathway represses human NK cell metabolism. J Immunol. (2018) 200:3934-41. doi: 10.4049/jimmunol.1701461

117. Netter P, Anft M, Watzl C. Termination of the activating NK cell immunological synapse is an active and regulated process. J Immunol. (2017) 199:2528-35. doi: 10.4049/jimmunol.1700394

118. Peng H, Jiang X, Chen Y, Sojka DK, Wei H, Gao X, et al. Liver-resident NK cells confer adaptive immunity in skin-contact inflammation. J Clin Invest. (2013) 123:1444-56. doi: 10.1172/JCI66381

119. Daussy C, Faure F, Mayol K, Viel S, Gasteiger G, Charrier E, et al. Tbet and Eomes instruct the development of two distinct natural killer cell lineages in the liver and in the bone marrow. J Exp Med. (2014) 211:563-77. doi: $10.1084 /$ jem. 20131560

120. Weizman OE, Song E, Adams NM, Hildreth AD, Riggan L, Krishna C, et al. Mouse cytomegalovirus-experienced ILC1s acquire a memory response dependent on the viral glycoprotein m12. Nat Immunol. (2019) 20:1004-11. doi: 10.1038/s41590-019-0430-1 
121. Zhou J, Peng H, Li K, Qu K, Wang B, Wu Y, et al. Liver-resident NK cells control antiviral activity of hepatic T cells via the PD-1-PD-L1 axis. Immunity. (2019) 50:403-17.e404. doi: 10.1016/j.immuni.2018.12.024

122. Monticelli LA, Buck MD, Flamar AL, Saenz SA, Tait Wojno ED, Yudanin NA, et al. Arginase 1 is an innate lymphoid-cell-intrinsic metabolic checkpoint controlling type 2 inflammation. Nat Immunol. (2016) 17:65665. doi: 10.1038/ni.3421

123. Li Q, Li D, Zhang X, Wan Q, Zhang W, Zheng M, et al. E3 ligase VHL promotes group 2 innate lymphoid cell maturation and function via glycolysis inhibition and induction of interleukin-33 receptor. Immunity. (2018) 48:258-70.e255. doi: 10.1016/j.immuni.2017.12.013

124. Galle-Treger L, Hurrell BP, Lewis G, Howard E, Jahani PS, Banie H, et al. Autophagy is critical for group 2 innate lymphoid cell metabolic homeostasis and effector function. J Allergy Clin Immunol. (2020) 145:502-17.e505. doi: 10.1016/j.jaci.2019.10.035

125. Gury-BenAri M, Thaiss CA, Serafini N, Winter DR, Giladi A, LaraAstiaso D, et al. The spectrum and regulatory landscape of intestinal innate lymphoid cells are shaped by the microbiome. Cell. (2016) 166:123146.e1213. doi: 10.1016/j.cell.2016.07.043

126. Di Luccia B, Gilfillan S, Cella M, Colonna M, Huang SC. ILC3s integrate glycolysis and mitochondrial production of reactive oxygen species to fulfill activation demands. J Exp Med. (2019) 216:2231-41. doi: 10.1084 /jem.20180549

127. Mamareli P, Kruse F, Lu CW, Guderian M, Floess S, Rox K, et al. Targeting cellular fatty acid synthesis limits $\mathrm{T}$ helper and innate lymphoid cell function during intestinal inflammation and infection. Mucosal Immunol. (2020). doi: 10.1038/s41385-020-0285-7. [Epub ahead of print].

128. Wilhelm C, Harrison OJ, Schmitt V, Pelletier M, Spencer SP, Urban JF Jr, et al. Critical role of fatty acid metabolism in ILC2-mediated barrier protection during malnutrition and helminth infection. J Exp Med. (2016) 213:1409-18. doi: $10.1084 /$ jem. 20151448

129. Robinette ML, Fuchs A, Cortez VS, Lee JS, Wang Y, Durum SK, et al. Transcriptional programs define molecular characteristics of innate lymphoid cell classes and subsets. Nat Immunol. (2015) 16:306-17. doi: 10.1038/ni.3094

130. Spencer SP, Wilhelm C, Yang Q, Hall JA, Bouladoux N, Boyd A, et al. Adaptation of innate lymphoid cells to a micronutrient deficiency promotes type 2 barrier immunity. Science. (2014) 343:432-7. doi: 10.1126/science. 1247606

131. Mielke LA, Jones SA, Raverdeau M, Higgs R, Stefanska A, Groom JR, et al. Retinoic acid expression associates with enhanced IL-22 production by gammadelta $\mathrm{T}$ cells and innate lymphoid cells and attenuation of intestinal inflammation. J Exp Med. (2013) 210:1117-24. doi: 10.1084/jem.20121588

132. Parameswaran R, Ramakrishnan P, Moreton SA, Xia Z, Hou Y, Lee DA, et al. Repression of GSK3 restores NK cell cytotoxicity in AML patients. Nat Commun. (2016) 7:11154. doi: 10.1038/ncomms11154

133. Cichocki F, Valamehr B, Bjordahl R, Zhang B, Rezner B, Rogers $\mathrm{P}$, et al. GSK3 inhibition drives maturation of NK cells and enhances their antitumor activity. Cancer Res. (2017) 77:5664-75. doi: 10.1158/0008-5472.CAN-17-0799

134. Zhao Y, Hu J, Li R, Song J, Kang Y, Liu S, et al. Enhanced NK cell adoptive antitumor effects against breast cancer in vitro via blockade of the transforming growth factor-beta signaling pathway. Onco Targets Ther. (2015) 8:1553-9. doi: 10.2147/OTT.S82616

135. Yvon ES, Burga R, Powell A, Cruz CR, Fernandes R, Barese C, et al. Cord blood natural killer cells expressing a dominant negative TGF-beta receptor: implications for adoptive immunotherapy for glioblastoma. Cytotherapy. (2017) 19:408-18. doi: 10.1016/j.jcyt.2016.12.005

136. Park A, Lee Y, Kim MS, Kang YJ, Park YJ, Jung H, et al. Prostaglandin E2 secreted by thyroid cancer cells contributes to immune escape through the suppression of natural killer (NK) cell cytotoxicity and NK cell differentiation. Front Immunol. (2018) 9:1859. doi: 10.3389/fimmu.2018.01859

137. Zhai L, Ladomersky E, Lenzen A, Nguyen B, Patel R, Lauing KL, et al. IDO1 in cancer: a Gemini of immune checkpoints. Cell Mol Immunol. (2018) 15:447-57. doi: 10.1038/cmi.2017.143

138. Hsu J, Hodgins JJ, Marathe M, Nicolai CJ, Bourgeois-Daigneault MC, Trevino TN, et al. Contribution of NK cells to immunotherapy mediated by PD-1/PD-L1 blockade. J Clin Invest. (2018) 128:4654-68. doi: 10.1172/JCI99317

139. Oyer JL, Gitto SB, Altomare DA, Copik AJ. PD-L1 blockade enhances anti-tumor efficacy of NK cells. Oncoimmunology. (2018) 7:e1509819. doi: 10.1080/2162402X.2018.1509819

140. Silver JS, Kearley J, Copenhaver AM, Sanden C, Mori M, Yu L, et al. Inflammatory triggers associated with exacerbations of COPD orchestrate plasticity of group 2 innate lymphoid cells in the lungs. Nat Immunol. (2016) 17:626-35. doi: 10.1038/ni.3443

141. Björkström NK, Ljunggren HG, Michaëlsson J. Emerging insights into natural killer cells in human peripheral tissues. Nat Rev Immunol. (2016) 16:310-20. doi: 10.1038/nri.2016.34

142. Cong J, Wei H. Natural killer cells in the lungs. Front Immunol. (2019) 10:1416. doi: 10.3389/fimmu.2019.01416

143. Hanna J, Goldman-Wohl D, Hamani Y, Avraham I, Greenfield C, NatansonYaron S, et al. Decidual NK cells regulate key developmental processes at the human fetal-maternal interface. Nat Med. (2006) 12:1065-74. doi: $10.1038 / \mathrm{nm} 1452$

144. Lash GE, Schiessl B, Kirkley M, Innes BA, Cooper A, Searle RF, et al. Expression of angiogenic growth factors by uterine natural killer cells during early pregnancy. J Leukoc Biol. (2006) 80:572-80. doi: 10.1189/jlb.040 6250

145. Jinushi M, Takehara T, Tatsumi T, Yamaguchi S, Sakamori $\mathrm{R}$, Hiramatsu $\mathrm{N}$, et al. Natural killer cell and hepatic cell interaction via NKG2A leads to dendritic cell-mediated induction of CD4 CD25 T cells with PD-1-dependent regulatory activities. Immunology. (2007) 120:73-82. doi: 10.1111/j.1365-2567.2006.02 479.x

146. Sun H, Sun C, Tian Z, Xiao W. NK cells in immunotolerant organs. Cell Mol Immunol. (2013) 10:202-12. doi: 10.1038/cmi.2013.9

147. Fu B, Zhou Y, Ni X, Tong X, Xu X, Dong Z, et al. Natural killer cells promote fetal development through the secretion of growth-promoting factors. Immunity. (2017) 47:1100-13.e1106. doi: 10.1016/j.immuni.2017.11.018

Conflict of Interest: The author declares that the research was conducted in the absence of any commercial or financial relationships that could be construed as a potential conflict of interest.

Copyright (c) 2020 Cong. This is an open-access article distributed under the terms of the Creative Commons Attribution License (CC BY). The use, distribution or reproduction in other forums is permitted, provided the original author(s) and the copyright owner(s) are credited and that the original publication in this journal is cited, in accordance with accepted academic practice. No use, distribution or reproduction is permitted which does not comply with these terms. 